\title{
Corruption as an Alternative to Limit Pricing
}

\author{
Raluca Elena Buia \\ Università Ca' Foscari di Venezia
}

First Draft: 21/10/2010

\begin{abstract}
We explore to what extent bribery can be an alternative way of fighting rivals' entry on the market when there is uncertainty about the degree of corruption in the public sector.

For high levels of corruption, "covert” fight through bribery is the optimal choice of an incumbent. For low degree of corruption, instead, the incumbent prefers to act strategically but overtly by playing a limit pricing game.
\end{abstract}

\section{Keywords}

Corruption, Bribery, Production licence, Moral cost, Covert/overt fight

\section{JEL Codes}

D21, D73, H40

Address for correspondence:

Raluca Elena Buia

Department of Economics

Ca' Foscari University of Venice

Cannaregio 873, Fondamenta S.Giobbe

30121 Venezia - Italy

Phone: (++39) 0412349105

Fax: (++39) 0412349176

e-mail: elenabui@unive.it 
This Working Paper is published under the auspices of the Department of Economics of the Ca' Foscari University of Venice. Opinions expressed herein are those of the authors and not those of the Department. The Working Paper series is designed to divulge preliminary or incomplete work, circulated to favour discussion and comments. Citation of this paper should consider its provisional character.

\section{Testo WP}

\section{Testo WP}




\section{Corruption as an Alternative to Limit Pricing}

October 21, 2010

\section{Introduction}

The literature on corruption has been receiving much attention in the last two decades, after the end of the Cold War. However, the research topics are far from being exhausted. Corruption is an extremely complex phenomenon with many aspects and implications.

One controversial issue in the field refers to the interdependencies between corruption and competition. The starting point in some of the existing studies is that the existence of corruption is strongly related to the existence of rents, for example Ades and Di Tella (1996, 1999), Tanzi (1998), Arnone and Iliopulis (2005). Certainly, if we speak about goods allocation, rents appear or are larger where the competition is less strong. Consequently, the conclusion of several studies is that the stronger the competition, the lower the registered levels of corruption. This idea finds support in the empirical evidence, for example Ades and Di Tella $(1996,1999)$ or Gurgur and Shah (2005). However, the relationship is not as clear as it seems.

Bliss and Di Tella (1997) try to explain the relationship between the competition level and corruption in a model in which competition is endogenous. They find that the existence of rents is not a necessary premise for corruption to exist and "operate". Corruption can appear also in markets characterized by perfect competition. This happens because corruption is able to generate rents by inducing less-efficient firms to exit the market.

On the same ground of the interactions between corruption and competition, the purpose of this paper is to address the question: can corruption become a barrier to entry of new competitors? And if yes, to what extent an incumbent prefers a "covert" bribery behavior to an "overt" strategically fighting entry.

There is no doubt that corruption is strongly related to decision power. In our paper a public (corruptible) official is delegated the task and hence the power to issue or deny the production licenses for the potential entrants on the market. We assume that any public employee is corruptible if he is offered a sufficiently large amount of money. However, the moral cost that the public employee has when behaving dishonestly is private information and this dictates the amount of bribe necessary to "persuade" him to favor the graft-payers. Departing from the models in the existing literature, in which the corrupt employee is asking a 
bribe to the potential interested party (Bliss and Di Tella 1997), in our paper the interested himself proposes a bribe but he does not have the certainty of the graft being accepted. The main results show that in economies where the public sector is characterized by low corruption an incumbent prefers to act strategically but overtly by playing a limit pricing game. Hence, at low levels, corruption does not affect competition and market outcomes. In an economy with high levels of corruption, instead, the incumbent finds the bribing alternative to be the most attractive, especially when the market is large and/or the cost of installing production capacity is low.

The paper is organized as follows: in Section 2 we introduce the model with the main assumptions. Sections 3 and 4 contain the descriptions with the main outcomes of the "covert" and "overt" behavior respectively. Section 5 analyzes the optimal choices of a profit-maximizing incumbent. Section 6 briefly explores the social implications of a bribery behavior. In section 7 we present two extensions of our model. Finally, Section 8 states the conclusions of the paper.

\section{The Model}

We consider a market characterized by the inverse demand function: $p=A-q$. Initially, there is only one firm (hereafter the incumbent) operating in the market. Entry of new firms is conditional on their obtaining a production licence certifying that all legal requirements (environmental constraints, quality or safety requirements etc.) are fulfilled. The entrant has to pay a fixed cost, $F$, representing a lump-sum tax, in exchange for the production licence ${ }^{1}$. A public official is delegated to issue the production licenses.

In order to produce one unit of the good any firm needs one unit of capacity and one unit of labor (firms face capacity constraints). One unit of capacity $\operatorname{costs} c_{0}$ while we assume, for convenience, that labor cost is 0 . We assume that the incumbent can invest in production capacity in a preliminary stage. Investments in production capacity are sunk costs and make credible the incumbent's commitment to given levels of production. The incumbent's cost function is:

$$
C_{i}\left(q_{i}\right)=c_{0} \cdot \max \left\{0, q_{i}-k\right\}+I_{k}
$$

where $I_{k}$ is the investment in capacity $k$ (sunk cost). In words, any quantity of the good $q$ has a marginal cost of 0 if it is inferior or equal to the existent production capacity $(q \leq k)$ while producing a quantity $q>k$ implies a marginal cost of $c_{0}$ for every unit of the good additional to the production capacity $k$.

The entrant's cost function is: $C(q)=F+c_{0} \cdot q_{e}$.

The public employee may be corruptible and, in exchange for a bribe, he can favor the graft-payers. The utility that the public official gets from receiving grafts is:

$$
U=B-\lambda
$$

${ }^{1}$ This fee is paid when the production licence is issued. Note that it is not a sunk cost but a fixed cost. 
where $B$ is the amount of the bribe that he receives while $\lambda$ is the moral cost of behaving dishonestly. The parameter $\lambda$ is private information but it is common knowledge that $\lambda \sim U[0, \Lambda]$. Note that the higher is $\Lambda$, the "less corruptible" is the employee; so, $\Lambda$ is inversely related to corruptibility.

In what follows we assume that there is one candidate (potential) entrant which satisfies all legal requirements for entering the market. The assumption that the entrant satisfies the legal requirements is not restrictive but it is part of the analysis, because we study here the influence that corruptibility of the public employee can have on the entry of qualified firms ${ }^{2}$. In what follows we restrict attention, for convenience, to the analysis of a situation in which the only player who can offer grafts is the incumbent. In a later extension we prove that the results are similar, with little variations, also for the case in which both the incumbent and the entrant can offer bribes (when they compete in bribes).

The timing of the game is the following:

- At date 1 the incumbent can choose between acting: i) "overtly" by playing a Dixit (1980) limit pricing game (commit to given levels of production by installing production capacity $k$ ); or ii) "covertly" by offering a graft in order to "persuade" the public official not to issue the production licence for the potential entrant. Once he decides for an action, he cannot switch to the other one in case of unsatisfactory result. Hence, in case the bribery game fails to deter entry, the incumbent cannot anymore install production capacities before the market game starts (cannot play anymore overt fighting through commitment). The consequence of this assumption will be clearer after we solve the game.

- At date 2, based on the incumbent's first move, the overt or covert subgame is played.

We describe in detail the covert and the overt subgames and their outcomes, separately, in the following sections.

Throughout the paper we assume, for convenience, that $c_{0}<\frac{1}{2} A$. Such an assumption is useful when studying the Dixit (1980) model called hereafter the "overt fight".

\section{Covert "fight"}

In this subgame the incumbent offers a bribe to the public official in order to "persuade" him not to issue the production licence for a candidate entrant. The game is sequential: in the first stage the incumbent offers a bribe to the public official. In the second stage the public employee decides whether to accept or reject the graft. If the employee accepts, he denies the production licence ${ }^{3}$, entry does not occur and the incumbent maintains a monopolistic position on

\footnotetext{
${ }^{2}$ In another paper we study the choice of qualifying or not when the public employee is corruptible.

${ }^{3} \mathrm{He}$ can find reasons to (postpone) block the entry.
} 
the market. If, instead, the public employee rejects the bribe offer, he issues the production licence and Cournot competition is played.

The choice between accepting or rejecting the bribe depends on the official's utility function and it is immediate that the public official acts dishonestly if:

$$
U(\text { accept }) \geq U(\text { reject }) ;
$$

that is, when:

$$
B-\lambda \geq 0 \Leftrightarrow \lambda \leq B
$$

This means that the public employee chooses to act dishonestly when his monetary gain from behaving so is greater than the moral cost of adopting such a behavior.

When the bribe is paid, the incumbent remains the only producer in the market and hence the monopoly outcome occurs. When the public official rejects the graft, entry occurs and each of the two firms gets the Cournot profit. Note that in such a case competitors are on equal positions, namely both have the same cost function, since the incumbent cannot anymore install production capacity before market game starts. Overall, the incumbent expects a level of profits of:

$$
E \Pi_{i}=\operatorname{Pr}(\lambda \leq B) \cdot\left(\Pi^{m}-B\right)+\operatorname{Pr}(\lambda>B) \cdot \Pi^{c}
$$

where $\Pi^{m}$ stands for monopoly profits while $\Pi^{c}$ represents the Cournot profits when none of the firms have previously installed capacity $(k=0)$.

Given our assumptions this becomes:

$$
E \Pi_{i}=\frac{B}{\Lambda} \cdot\left(\Pi^{m}-B\right)+\left(1-\frac{B}{\Lambda}\right) \cdot \Pi^{c}
$$

and from the first order condition we get the optimal bribe:

$$
B^{*}=\frac{1}{2}\left(\Pi^{m}-\Pi^{c}\right)
$$

Substituting for $\Pi^{m}$ and $\Pi^{c}$ we get:

$$
B^{*}=\frac{5}{72}\left(A-c_{0}\right)^{2}
$$

Note that the optimal bribe is increasing with $A$ (the dimension of the market) and decreasing in $c_{0}$. This is due to the fact that the incumbent's gain from deterring entry is increasing with $A$ but decreasing in $c_{0}$. We can easily observe that both $\Pi^{m}$ and $\Pi^{c}$ increase with the difference $\left(A-c_{0}\right)$ but $\Pi^{m}$ increases faster than $\Pi^{c}$ does. This makes it worth to the incumbent to pay a higher bribe which guarantees him a higher probability of deterring entry and maintaining a monopoly position.

Based on the relationship between $\Lambda$ e $\frac{5}{72}\left(A-c_{0}\right)^{2}$, it is useful to distinguish two situations: 
- $\Lambda<\frac{5}{72}\left(A-c_{0}\right)^{2}$. In this case, offering a bribe of amount $\frac{5}{72}\left(A-c_{0}\right)^{2}$ is dominated by offering a graft of $\Lambda$. We remind that $\Lambda$ represents the upper bound of the moral cost of behaving dishonestly (the maximum possible moral cost of behaving dishonestly). This means that any public official has at most a moral cost of $\Lambda$. So, offering a graft of $\Lambda$ compensates for sure any type of public official for his moral costs of behaving dishonestly. Consequently, if a graft $\Lambda$ is offered, it is accepted with certainty and hence, the entrant's application for production licence is rejected. This means that paying $\Lambda<\frac{5}{72}\left(A-c_{0}\right)^{2}$ makes the incumbent better off than paying a graft of $\frac{5}{72}\left(A-c_{0}\right)^{2}$.

- $\Lambda \geq \frac{5}{72}\left(A-c_{0}\right)^{2}$. In this case the optimal bribe to be offered is $B^{*}=$ $\frac{5}{72}\left(A-c_{0}\right)^{2}$.

We study both cases in more detail when we do the comparative analysis in Section 5 .

Given the above considerations, in order to have a complete and correct expression for the optimal bribe we redefine it as below:

$$
B^{*}=\min \left\{\Lambda, \frac{5}{72}\left(A-c_{0}\right)^{2}\right\}
$$

Then, given a dishonest behavior of the incumbent, the probability that entry is blocked by a corrupt public official is:

$$
\operatorname{Pr}(\text { deny p.l. })=\operatorname{Pr}\left(B^{*} \geq \lambda\right)=\min \left\{\frac{5}{72 \Lambda}\left(A-c_{0}\right)^{2}, 1\right\}
$$

\section{Overt "fight"}

In this subgame, the incumbent optimally chooses the production capacity to install. Practically, such a decision is equivalent to choosing the best action among the following possibilities: "fighting" the entrant (by playing limit pricing) or strategically accomodating entry (by playing Stackelberg or Cournot whichever is optimal for the incumbent).

In what follows, we compute the optimal production capacity $k^{*}$ in various scenarios, using the Dixit (1980) model ${ }^{4}$. Intermediary results, namely the outcomes of the different situations (monopoly, Cournot without capacity commitments $\left(k_{i}=0\right)$, Cournot when the incumbent's capacity is $k=\infty$ and Stackelberg), necessary in order to compute $k^{*}$ are reproduced in the Appendix. Based on the entrant's level of profits, we distinguish three main situations:

1. Blockaded monopoly: In this case the entrant has negative profits in the common Cournot competition. The limit quantity is lower than $q_{i}^{c}$ and, consequently, the incumbent can act as a monopolist while still deterring entry.

\footnotetext{
${ }^{4}$ We follow the approach of Tirole (1994) and Church and Ware (2001).
} 
Producing the monopoly quantity and hence installing the monopoly capacity is the incumbent's optimal action in this case.

$$
k^{*}=q_{i}^{S}
$$

where $q_{i}^{S}$ is the optimal quantity of a leader under Stackelberg competition. This situation can occur for high levels of the entry fee, $F$, namely when:

$$
F \geq \frac{1}{9}\left(A-c_{0}\right)^{2}
$$

2. Strategic deterrence/accomodation: In such a case the entrant's profits are positive in a Cournot game in which players are on equal positions (players have the same marginal cost - none of the players have positive production capacity before the game starts) but negative in the equilibrium of a game in which the incumbent has an infinite production capacity ${ }^{5}$. This means that the limit quantity is comprised between $q_{i}^{c}$ and $q_{i}^{c k}$ (see Appendix), where $q_{i}^{c k}$ is the optimal supply of the incumbent in a Cournot competition in which the incumbent has infinite production capacity ${ }^{6}$. Such a situation happens when:

$$
\frac{1}{9}\left(A-2 c_{0}\right)^{2} \leq F<\frac{1}{9}\left(A-c_{0}\right)^{2}
$$

that is, when the entry fee is significantly high, though not as large as in the previous situation. In such a case the incumbent could profitably play "limit pricing" but, since his final purpose is (not "entry deterrence" but) profit maximization he chooses that action which maximizes his payoff. Based on the incumbent's optimal action we distinguish the following situations:

- Blockaded monopoly: This situation, which happens for levels of the entry fee that simultaneously satisfy:

$$
\max \left\{\frac{1}{9}\left(A-2 c_{0}\right)^{2}, \frac{1}{16}\left(A-c_{0}\right)^{2}\right\} \leq F<\frac{1}{9}\left(A-c_{0}\right)^{2}
$$

is characterized by the fact that the "limit quantity" is lower than the monopoly output. Consequently, it becomes optimal for the incumbent to install the monopoly capacity and produce the monopoly output while successfully deterring entry.

- Limit pricing: The limit quantity becomes optimal $\left(k^{*}=q^{l}\right)$ in situations in which the entrant has to pay a significantly positive entry fee but still $F$ is not very large:

$$
\max ^{7}\left\{\frac{1}{9}\left(A-2 c_{0}\right)^{2}, \frac{(3-2 \sqrt{2})}{32}\left(A-c_{0}\right)^{2}\right\} \leq F<\frac{1}{16}\left(A-c_{0}\right)^{2}
$$

\footnotetext{
${ }^{5}$ The Cournot game when the incumbent's production capacity is zero, is different from the Cournot game in which the incumbent capacity is infinity because in the two games the incumbent has different cost functions (see the description of the model on page 2).

${ }^{6}$ This is equivalent to the incumbent having a marginal cost of 0 while the marginal cost of the entrant remains $c_{0}$.

${ }^{7}$ This is $\frac{1}{9}\left(A-2 c_{0}\right)^{2}$ for $A>2,28 c_{0}$ and $\frac{3-2 \sqrt{2}}{32}\left(A-c_{0}\right)^{2}$ otherwise.
} 
In such a situation, the incumbent's commitment to the monopoly output does not keep the entrant out of the market. The level of the entry fee, although significant, still allows the entrant to obtain positive profits if the incumbent produces his monopoly quantity. Note that such a situation can occur only if $c_{0} \geq \frac{1}{5} A^{8}$.

- Stackelberg optimality: This case arises only for significantly high capacity $\operatorname{costs}^{9} c_{0}$, and the levels of entry fee that support Stackelberg are:

$$
\frac{1}{9}\left(A-2 c_{0}\right)^{2} \leq F<\frac{(3-2 \sqrt{2})}{32}\left(A-c_{0}\right)^{2}
$$

Note that Stackelberg optimality is induced by a situation in which the entry fee is positive but low. This is due to the fact that the level of the entry fee has a direct influence on the limit quantity. The limit quantity, $q^{l}$ is negatively related to $F$ (see Appendix for the expression of $q^{l}$ ) and hence a low entry fee induces a large limit quantity, $q^{l}$ and, consequently, a low price. Then, for high levels of the capacity cost, $c_{0}$, the additional gains from deterring entry may be offset by the higher sunk costs for installing capacity $q^{l}$. Consequently, when costs $c_{0}$ are large while the entry fee $F$, is rather small, it becomes optimal for the incumbent to strategically accomodate entry by playing Stackelberg instead of deterring entry at all costs.

3. Optimal accomodation: This is the situation in which the profits of the potential entrant are positive in "the worst possible post-entry equilibrium" (when the incumbent's installed capacity is unlimited, $k=\infty$ ). Optimal accomodation is supported by very low levels of the entry fee:

$$
F<\frac{1}{9}\left(A-2 c_{0}\right)^{2}
$$

In such a situation, entry deterrence (limit pricing) is never an optimal choice for the incumbent who chooses his optimal action among the possible ways of accomodating entry. The reason is, again, that the low entry fee (determining a high limit quantity ${ }^{10}$ and correspondingly a low limit price) make the limit quantity an alternative with extremely high opportunity cost even when $c_{0}$, the capacity installing cost, is low. The additional gains from deterring entry are not large enough to compensate for the decrease in price that accompanies large levels of $q_{l}$.

\footnotetext{
${ }^{8}$ This condition assures that $\frac{1}{9}\left(A-2 c_{0}\right)^{2}<\frac{1}{16}\left(A-c_{0}\right)^{2}$. When $c_{0}<\frac{1}{5} A$, instead, all values of the entry fee considered promote $q^{m}$ as optimal strategy.

${ }^{9}$ Only for those values of $c_{0}$ for which $\frac{1}{9}\left(A-2 c_{0}\right)^{2}<\frac{(3-2 \sqrt{2})}{32}\left(A-c_{0}\right)^{2}$, namely for $c_{0}>\frac{1+12 \sqrt{2}}{41} A(\approx 0.4383 A)$.

${ }^{10}$ In this situation we have that $q^{l}>q^{c k}$. We remind that $q^{c k}$ is the optimal quantity to be produced by a firm in a Cournot game in which the firm has an infinite production capacity (or a marginal production cost of 0 ) while the rival has no installed capacity (or a marginal cost of $\left.c_{0}\right)$.
} 
This situation also includes the special case in which there is no entry fee.

Depending on the incumbent's optimal move we identify two different situations:

- Stackelberg optimality: This case, which can occur only for large capacity costs: $c_{0}>\frac{1}{5} A$, is the situation in which the incumbent's profits are maximized by playing Stackelberg and is practically characterized by $q_{1}^{c}<q_{1}^{S}<q_{1}^{c k}$.

- Cournot dominance: Finally, this is the case in which playing Cournot with capacity commitments, that is, installing capacity $k=q_{1}^{c k}$ and producing $q_{1}^{c k}$ is the best choice of the incumbent. This is optimal only when $c_{0}$ is low: $c_{0}<\frac{1}{5} A$, and hence $q_{1}^{S}>q_{1}^{c k}$.

\section{Optimal choice and main outcomes}

We identify now the situations in which overt fight is optimal for the incumbent and those that, on the contrary, support covert fight as the best incumbent's strategy. In addition, we establish, on one hand, in which circumstances entry occurs and, on the other hand, to what extent the degree of corruption negatively influences competition.

In what follows, we separately analyze the two cases identified in section 3 , namely the situation when the perceived degree of corruption is medium-low and the situation when corruption is high, respectively.

\subsection{Medium-low corruption, $\Lambda \geq \frac{5}{72}\left(A-c_{0}\right)^{2}$}

In order to simplify the analysis we group together all the cases in which the incumbent behaves in the same way, no matter which are the causes that determine such a behavior.

Blockaded monopoly versus bribe: As we discussed above, we have blockaded monopoly when the entry fee is significantly high, inducing a very low level of the limit quantity $q_{1}^{l}<q^{c}$ or $q_{1}^{l}<q^{m}$ :

$$
F \geq \max \left\{\frac{1}{9}\left(A-2 c_{0}\right)^{2}, \frac{1}{16}\left(A-c_{0}\right)^{2}\right\}
$$

Then, the incumbent's best choice is to install the monopoly capacity $\left(k^{*}=q^{m}\right)$ and to produce at the monopoly level. Such a behavior deters entry while maximizing the incumbent's payoffs.

This is the simplest possible situation because the incumbent cannot be better off by behaving dishonestly. Hence, we can assert that for high levels of the entry fee the incumbent's optimal strategy is to fight overtly.

Proposition 1. For very high levels of the entry fee a covert fight is never optimal for an incumbent. 
Limit quantity versus bribe: When limit quantity is the optimal legal action,

$$
\max \left\{\frac{1}{9}\left(A-2 c_{0}\right)^{2}, \frac{(3-2 \sqrt{2})}{32}\left(A-c_{0}\right)^{2}\right\} \leq F<\frac{1}{16}\left(A-c_{0}\right)^{2} \text { and } c_{0}>\frac{1}{5} A .
$$

Computing the difference between the expected profits from a covert fight and the profits from an overt fight we get:

$$
E \Pi_{i}-\Pi_{i}^{l}=4 F-2 \sqrt{F}\left(A-c_{0}\right)+\frac{25}{5184 \Lambda}\left(A-c_{0}\right)^{4}+\frac{1}{9}\left(A-c_{0}\right)^{2}
$$

It is easy to observe that the difference $E \Pi_{i}-\Pi_{i}^{l}$ is negatively related to the level of the upper-bound, $\Lambda$ : the higher is $\Lambda$, the lower is the probability that the public employee accepts the bribe and blocks entry and hence the lower is the relative profitability of a dishonest behavior (recall that $\Lambda$ is the maximum moral cost to the public official from behaving dishonestly). Indeed, we find out that:

only for:

$$
E \Pi_{i}-\Pi_{i}^{l} \geq 0
$$

$$
\Lambda \leq \frac{25\left(A-c_{0}\right)^{4}}{5184\left(-4 F+2 \sqrt{F}\left(A-c_{0}\right)-\frac{1}{9}\left(A-c_{0}\right)^{2}\right)}
$$

The right hand side of the above expression is a threshold and we denote it by $\Lambda^{l}$. Note that this is strictly decreasing with the value of the entry fee $F$ : the higher is $F$, the lower is the range of the values $\Lambda$ that induce covert behavior for the incumbent. For a given value of the entry fee, the incumbent finds it optimal to behave dishonestly only if such values of the entry fee are accompanied by sufficiently low levels of $\Lambda$ (that is, high probability of corruption). The intuition behind this is the following: a high entry fee determines a low limit quantity $q_{l}$, and this implies that an overt fight is not very costly. Hence, under the circumstances, the incumbent prefers a covert behavior to overtly playing $q^{l}$ only if the probability of success of the bribing strategy is high ( $\Lambda$ is low). If the value of $\Lambda$ is high the incumbent finds it optimal to play overtly.

Before any further comments, we remind that we are here in a situation in which the level of corruption is not high (we assumed in this case that $\Lambda \geq$ $\left.\frac{5}{72}\left(A-c_{0}\right)^{2}\right)$ so we check if in such a case the incumbent ever acts covertly. By comparing the domain of $\Lambda$ with the threshold $\Lambda^{l}$ we find out that $\Lambda^{l} \geq$ $\frac{5}{72}\left(A-c_{0}\right)^{2}$ for those values of $F$ that satisfy:

$$
\sqrt{F} \leq \frac{6-\sqrt{10}}{24}\left(A-c_{0}\right) \approx 0,118\left(A-c_{0}\right)
$$

while the threshold is always lower otherwise. We can thus affirm that the incumbent finds it preferable to play dishonestly only if the entry fee $F$ is low and, at the same time, the moral cost of the public official is not too high:

$$
\frac{5}{72}\left(A-c_{0}\right)^{2} \leq \Lambda \leq \frac{25\left(A-c_{0}\right)^{4}}{5184\left(-4 F+2 \sqrt{F}\left(A-c_{0}\right)-\frac{1}{9}\left(A-c_{0}\right)^{2}\right)}
$$


We remark that, in this case the perception of relatively high corruption may be "beneficial" in the sense that it switches the behavior of the incumbent from strategically playing limit pricing, with zero probability of entry, to bribery, which guarantees a positive probability of entry.

Just in order to complete the analysis we add that for a significantly high entry fee, $\sqrt{F} \geq \frac{6-\sqrt{10}}{24}\left(A-c_{0}\right) \approx 0.118\left(A-c_{0}\right)$, it is always verified that:

$\max \left\{\frac{5}{72}\left(A-c_{0}\right)^{2}, \frac{25\left(A-c_{0}\right)^{4}}{5184\left(-4 F+2 \sqrt{F}\left(A-c_{0}\right)-\frac{1}{9}\left(A-c_{0}\right)^{2}\right)}\right\}=\frac{5}{72}\left(A-c_{0}\right)^{2}$,

In such a case ${ }^{11}$ the incumbent has no incentive to act covertly, but he always deters entry by means of an overt behavior.

Hence, we can say that, under medium-low corruption, $\Lambda \geq \frac{5}{72}\left(A-c_{0}\right)^{2}$, large levels of the entry fee support limit pricing against the covert alternative of graft payments.

Stackelberg versus bribe: As we previously saw, the Stackelberg game is supported by:

$$
F \leq \max \left\{\frac{1}{9}\left(A-2 c_{0}\right)^{2}, \frac{(3-2 \sqrt{2})}{32}\left(A-c_{0}\right)^{2}\right\} \text { and } c_{0} \geq \frac{1}{5} A
$$

This combines two different situations (see Section 4):

- a significantly positive, although not very large, entry fee when this is accompanied by large capacity costs, $c_{0}$ :

$$
\frac{1}{9}\left(A-2 c_{0}\right)^{2} \leq F<\frac{(3-2 \sqrt{2})}{32}\left(A-c_{0}\right)^{2} \text { and } \quad 0.4383 \cdot A \leq c_{0} \leq \frac{1}{2} A
$$

- low levels of the entry fee, $F<\frac{1}{9}\left(A-2 c_{0}\right)^{2}$, when, in addition, the (relative) capacity cost is medium-large, $\frac{1}{5} A<c_{0}<\frac{1}{2} A$.

When playing Stackelberg, the incumbent gets a level of profit equal to:

$$
\Pi_{i}^{S}=\frac{1}{8}\left(A-c_{0}\right)^{2}
$$

Comparing this with the expected profit from playing covertly, we find out that for the incumbent is optimal to act dishonestly whenever:

$$
\frac{5}{72}\left(A-c_{0}\right)^{2} \leq \Lambda \leq \frac{25}{72}\left(A-c_{0}\right)^{2}
$$

When, instead, $\Lambda>\frac{25}{72}\left(A-c_{0}\right)^{2}$, the incumbent is better off by acting strategically but overtly.

${ }^{11}$ The range of moral costs which support bribery is not comprised in our reference domain. 
In words, this means that the incumbent has incentives to behave covertly when the degree of corruption is significantly high; this is expressed in our model by medium-low moral costs of a covert behavior (low $\Lambda$ ). Note that the range of values $\Lambda$ that support covert behavior is increasing with the amount $\left(A-c_{0}\right)^{2}$. Hence, the range of values $\Lambda$ for which offering a bribe to the public official is the incumbent's optimal action is increasing with the value of $A$ and decreasing with the level of the capacity-installing costs, $c_{0}$. This happens because larger (market dimensions) $A$, and/or lower capacity-installing costs increase the monopoly profits more than the leader's Stackelberg ones. This makes more desirable a situation of monopoly and hence, makes it worth taking more risk and behave dishonestly in order to block entry, even under lower levels of corruption (higher $\left.\Lambda^{12}\right)$. For lower $\left(A-c_{0}\right)^{2}$ instead, if the employee's moral costs are not sensibly low, the incumbent finds it optimal to act overtly by playing Stackelberg. That is, if lower profits from monopoly are not compensated, by a higher probability of corruption (higher probability of success in deterring entry), then profits from playing Stackelberg are higher than those that the incumbent expects from playing "bribe".

Analyzing entry, we can say that for large $\Lambda$ entry occurs for any value of the entry fee considered. This happens because, when the incumbent perceives low degree of corruption in the public sector, he chooses to strategically play Stackelberg instead of offering grafts. On the other hand, for medium-low $\Lambda$, that is, when the perceived level of corruption is rather high, the incumbent expects to get more profit by bribing the public employee in exchange for maintaining a monopoly position. In this situation entry happens with a probability

$$
\operatorname{Pr}(\text { reject bribe })=\operatorname{Pr}\left(\lambda>B^{*}\right)=1-\frac{5}{72 \Lambda}\left(A-c_{0}\right)^{2}
$$

which is increasing with $\Lambda$ and decreasing with the difference $\left(A-c_{0}\right)$.

Going further with our analysis, we can say that the negative effects of high corruption are double-sided. The perception of a high level of corruption (low $\Lambda$ ) induces the incumbent to opt for the covert behavior. Then, on one hand, if the moral cost of the public employee, $\lambda$, is indeed low, the bribe is accepted and entry does not occur. On the other hand, ifthe public official has a high moral cost, $\lambda>B^{*}$, he rejects the bribe but still this leads to Cournot competition while an overt behavior would have led to Stackelberg competition which is better off from both the social and consumers' perspective. Hence, we can assert that the perception of strong corruption is bad even when it does not reduce competition since it alters the behavior of the incumbent with negative effects on the consumers and society in general.

Cournot versus bribe: First of all, recall that when the incumbent acts overtly, it is optimal for him to play a Cournot game only when both the entry fee and the capacity costs are low,

$$
F<\frac{1}{9}\left(A-2 c_{0}\right)^{2} \text { and } c_{0} \leq \frac{1}{5} A
$$

\footnotetext{
${ }^{12}$ This is equivalent to a higher probability that the public employee rejects the bribe.
} 
In such a situation the optimal overt action for the incumbent is to previously install capacity $k^{*}=\frac{A+c_{0}}{3}$ and to produce a quantity equal to this capacity. The profits that he gets are:

$$
\Pi_{1 k}^{C}=\frac{1}{9}\left(A^{2}-A c_{0}-2 c_{0}\right)
$$

As above, we are interested if under such levels of the entry fee and capacity cost the incumbent would be better off by fighting overtly or covertly. Comparing the profits that the firm expects in each of the two cases, we obtain that the incumbent is better off by playing Cournot when:

$$
\Lambda \geq \frac{25\left(A-c_{0}\right)^{4}}{576 c_{0}\left(A-3 c_{0}\right)}
$$

and finds it optimal to play covertly instead, when $\Lambda$ is lower than the above threshold which we denote $\Lambda^{C}$. In light of the previous results, this one is intuitive: the incumbent finds attractive to play Cournot only when the level of corruption is very low (that is, for very large $\Lambda$ ). Otherwise, for significant probability of corruption, $\Lambda=\Lambda^{C}-\epsilon, \epsilon>0$, the incumbent expects larger profits from acting dishonestly and hence prefers playing "bribe". Similarly to the previous case, we observe that the threshold is increasing with $A$ and decreasing with the values of $c_{0}$. This means that the larger is $A$ (the dimension of the market) and/or the lower is the capacity-cost, $c_{0}$, the larger is the range of values $\Lambda$ which induce the incumbent to behave dishonestly.

Summing up our findings, we can state the following conclusions:

Proposition 2. When the level of corruption is high, bribery reduces competition on the market, substituting limit pricing. When the degree of corruption is low, it has no effect on the market competition. The range of values $\Lambda$ which support covert behavior is increasing with the dimension of the market, $A$ and decreasing with the capacity installing cost, $c_{0}$.

Proposition 3. The incentive to choose a covert behavior is stronger when the optimal overt action is Cournot than when the best overt action is Stackelberg which, in turn is stronger than in the case of limit pricing optimality: $\Lambda^{l}>$ $\Lambda^{S}>\Lambda^{C}$

\subsection{High corruption, $\Lambda<\frac{5}{72}\left(A-c_{0}\right)^{2}$}

In such a case the optimal bribe:

$$
B^{*}=\min \left\{\Lambda, \frac{5}{72}\left(A-c_{0}\right)^{2}\right\}=\Lambda
$$

that is, the optimal bribe is equal to the maximum possible moral cost of the public official. The main feature of this situation is that the public employee 
always accepts the bribe proposed to him and, consequently, if the incumbent decides to act covertly, entry is always blocked and the game has a monopoly outcome. This is a rather trivial and very rare situation of a totally corrupt public sector. However, it may still be representative for countries like SubSaharan countries where the level of corruption is extremely high.

Analyzing quickly this situation, we can immediately say two things: on one hand, for those levels of the entry fee that promote Stackelberg or Cournot as the optimal incumbent's overt choice, the dishonest behavior is always preferred by the incumbent who is certain that paying a bribe of $\Lambda$ guarantees him a position of monopoly on the market. Certainly, in such situations, the consumers' surplus and the social welfare are the monopoly ones and hence lower than in a situation in which the incumbent plays honestly. On the other hand, when the entry fee is very large ${ }^{13}$, this leads again to a situation of blockaded monopoly in which the incumbent maintains his position without having to play covertly but he just needs to install production capacity $k^{*}=q^{m}$ and produce the monopoly quantity.

The most interesting situation here is when the entry fee is significantly high, so that it promotes limit pricing as the optimal strategy in an overt subgame ${ }^{14}$. Comparing the profit from a limit pricing action:

$$
\Pi^{l}=2 \sqrt{F}\left(A-c_{0}\right)-4 F
$$

to those expected when playing bribery:

$$
E \Pi^{B}=\frac{1}{4}\left(A-c_{0}\right)^{2}-\Lambda
$$

we obtain that the incumbent is better off by playing covertly whenever the probability of corruption is lower than the threshold, $\bar{\Lambda}$ :

$$
\Lambda<\bar{\Lambda}=\frac{1}{4}\left(A-c_{0}\right)^{2}-2 \sqrt{F}\left(A-c_{0}\right)+4 F
$$

In words, for those values of $F$ that promote limit quantity as the optimal overt action and for significantly high levels of the parameter $\Lambda$, the incumbent finds it less costly to act honestly. When $\Lambda$ is large, the two combined effects: i) overt entry deterrence is not too costly due to the fact that $F$ is significantly positive (inducing a lower $q^{l}$ ) and ii) the high costs of playing covertly (the bribe is equal to $\Lambda$ in this case), induce the incumbent to act honestly, on his own. On the contrary, when $\Lambda<\bar{\Lambda}$, the low cost of playing limit pricing is offset by the even lower cost of deterring entry by paying a bribe.

We observe that the threshold $\bar{\Lambda}$ is positively related to the difference $\left(A-c_{0}\right)$, hence is decreasing with the capacity-installing cost, $c_{0}$ while it is increasing with the parameter $A$. This means that the range of moral costs from corruption, $\Lambda$, which support a covert behavior of the incumbent is larger when the difference $\left(A-c_{0}\right)$ is larger. This reflects the fact that larger markets and/or lower

\footnotetext{
${ }^{13}$ See Blockaded monopoly on page 6 .

${ }^{14}$ See "Limit pricing" on page 7.
} 
production costs makes worth paying more in order to maintain an unaltered monopoly position.

Summing up, we can formulate the following result:

Proposition 4. In an extremely corrupt society, competition is always negated because entry never occurs.

The explanation of this result is that in economies with high degree of corruption either the incumbent deters the rival's entry by means of practicing limit pricing or entry is blocked by a corrupt public official who does not issue a production licence to the potential entrant.

\section{Social implications}

We analyze now the consumers' surplus and the social welfare under the overt and covert behavior respectively. We compute the social welfare as the total amount of the producers' profits and the consumers' surpluses. Note that the entry fee does not affect the level of social welfare since it is just a transfer from the entrant to the Government. Then, the social welfare under overt behavior is given by:

$$
W=\Pi_{i}+\Pi_{e}+S_{c}
$$

where $\Pi_{i}$ stands for the incumbent's profit, $\Pi_{e}$ for the entrant's gross profit ${ }^{15}$ from production and $S_{c}$ represents the consumers' surplus. The amount of the social welfare defined as above, varies according to the type of competition in the market (see appendix for detailed formula).

Under covert behavior the expected welfare is:

$$
\begin{aligned}
E W^{B} & =\operatorname{Pr}(\text { deny p.l. }) \cdot\left(\Pi_{i}^{m}+S_{c}^{m}\right)+\operatorname{Pr}(\text { issue p.l. }) \cdot\left(\Pi_{i}^{C}+\Pi_{e}^{C}+S_{C}^{C}\right) \\
& =\left(A-c_{0}\right)^{2} \cdot\left[\frac{4}{9}-\frac{25}{5184 \Lambda}\left(A-c_{0}\right)^{2}\right]
\end{aligned}
$$

with low degree of corruption and:

$$
E W_{h}^{B}=W^{m}=\frac{3}{8}\left(A-c_{0}\right)^{2}
$$

under high corruption. Note that the bribe, being a transfer, does not enter the welfare function directly, but influences welfare only indirectly, by means of its effects on competition (hence on supply and equilibrium prices).

Low corruption. When the level of the entry fee supports limit pricing as the optimal overt action, we observe that consumers and society are worse off under bribery when the entry fee is relatively low or when a large entry fee is accompanied by a high level of corruption (low $\Lambda$ ). When, instead, a large level

\footnotetext{
${ }^{15}$ The profit before subtracting the entry fee.
} 
of the entry fee is accompanied by a low degree of corruption, limit pricing leads to lower levels of welfare and consumers' surplus than a covert action would do. The explanation is the following. On one hand, under limit pricing both the consumers' surplus and the social welfare depend negatively on the level of the entry fee. This is because the lower is the entry fee, the higher is the production that the incumbent needs to commit to, and to produce in order to deter entry. Consequently, a low entry fee implies a high limit quantity, $q^{l}$, that is, a larger supply and a lower equilibrium price, increasing the consumers' surplus and social welfare.

On the other hand, when $\Lambda$ is significantly large, the probability that the public official rejects the bribe and a Cournot game is played is high. Then, a low entry fee leads to higher welfare under limit pricing than under bribery, but large levels of $F$ accompanied by large $\Lambda$ induce higher levels of expected welfare under bribery, due to the combined effect of two elements: 1) low levels of $q_{l}$ implying high equilibrium prices of an overt behavior, together with 2 ) the reduced probability that the public employee behaves dishonestly and, consequently, the high probability of entry under a covert incumbent's behavior.

When the optimal incumbent's overt action is committing to Stackelberg competition we easily note that social welfare and consumers' surplus are always lower under bribery than under Stackelberg. The explanation is rather simple. In the Stackelberg setup the equilibrium supply is always larger and the price is lower than in both monopoly and Cournot competition. This makes consumers always better off under Stackelberg than both under monopoly or Cournot. Given that the expected welfare under bribery is a linear combination of the welfare under monopoly and the welfare under Cournot competition (where the weights are the probability that the public official accepts and the probability that he rejects the bribe respectively), it is immediate that welfare under Stackelberg is higher than the expected welfare under corruption. This confirms that incumbent's overt actions are more desirable for the society than covert behavior is, even when the probability of succeeding in blocking entry is lower (the probability that the graft is rejected is higher).

Finally, when Cournot is the incumbent's optimal overt move, we can immediately prove that both consumers and society are worse off under bribery. The explanation is similar to the Stackelberg case: Cournot where the incumbent has infinite capacity is always preferable from a social point of view to both monopoly and common Cournot.

High corruption. We only remark that under high corruption the outcome of a covert behavior is monopoly. Consequently, the consumers' surplus and the social welfare are always lower under covert than under overt behavior.

Proposition 5. i) When the entry fee $F$ is low the consumers and the society are always better off under the incumbent's overt behavior. ii) However, under large $F$, supporting limit pricing, and low corruption (high $\Lambda$ ) the social welfare and the consumers' surplus are both larger under bribery. iii) When the degree 
of corruption is high an overt behavior is always preferred by the consumers and the society.

\section{$7 \quad$ Extensions}

In this section we briefly summarize some results, obtained when altering two of our initial assumptions: i) we allow the entrant to bribe as well; ii) we assume that the incumbent has a positive production capacity before the game starts (before date 0 ).

\subsection{Competition in Bribes}

We explore how our previous results change when we allow both rivals, the incumbent and the entrant, to compete by simultaneously offering a bribe to the public official.

First of all, we remark that, given our assumption that the entrant satisfies all legal requirements, it makes sense for him to offer a bribe only when the incumbent fights covertly. When accepted, in exchange for the graft, the public official favors the bribe payer.

In a covert subgame, the public employee accepts the highest bribe between the two if this is larger than his moral cost from behaving dishonestly and he rejects both grafts if the highest one is lower than $\lambda$. We assume that, when the incumbent and the entrant's bribes are equal, the public official accepts the incumbent's offer ${ }^{16}$. Denoting with $B$ and $b$ the bribes offered by the incumbent and the entrant respectively, the utility function of the public employee in a covert subgame is:

$$
U_{p e}=\left\{\begin{array}{l}
B \text { if } B \geq \max \{b, \lambda\} \\
b \text { if } b>\max \{B, \lambda\} \\
0 \text { if } \lambda>\max \{b, B\}
\end{array}\right.
$$

In the equilibrium the entrant offers a bribe:

$$
b^{*}=\Pi^{c}-F
$$

that is, his optimal bribe is equal to his net profit.

The incumbent's optimal graft is:

$$
B^{*}=\max \left\{b^{*}, \min \left\{\Lambda, \frac{1}{2}\left(\Pi^{m}-\Pi^{c}\right)\right\}\right\}
$$

We remark that the incumbent's optimal bribe is always at least as large as the entrant's. Hence, in a covert subgame either the incumbent's graft is accepted or both bribes are rejected. Note that, as one may expect, the incumbent's optimal bribe in this case is always larger than in the situation described in section 3 .

\footnotetext{
${ }^{16}$ It is not unnatural to assume this since, in such cases, the incumbent would effectively bribe $b+\epsilon$, with $\epsilon>0, \epsilon \rightarrow 0$.
} 
Performing a similar analysis with the one in Section 5, we find out that the results are similar to the ones we obtained for the case of a unique bribe-payer (the incumbent) with the following main variations:

1. Based on the values of the entry fee $F$, and the maximum moral cost $\Lambda$, in this case we can identify four different situations with respect to the optimal incumbent's bribe.

a) When $\Lambda \geq \frac{5}{72}\left(A-c_{0}\right)^{2}$ and $F \geq \frac{1}{24}\left(A-c_{0}\right)^{2}$, that is, medium-low corruption and large entry fee ${ }^{17}$, the incumbent's optimal bribe is exactly the one in subsection 5.1, namely,

$$
B^{*}=\frac{5}{72}\left(A-c_{0}\right)^{2}
$$

b) Under relatively low degree of corruption, $\Lambda \geq \frac{1}{9}\left(A-c_{0}\right)^{2}-F$ and low $F$, $F<\frac{1}{24}\left(A-c_{0}\right)^{2}$, the optimal incumbent's bribe is:

$$
B^{*}=\frac{1}{9}\left(A-c_{0}\right)^{2}-F \leq \Lambda
$$

c) For low moral costs, $\Lambda<\frac{5}{72}\left(A-c_{0}\right)^{2}$ and a large entry fee, $F \geq \frac{1}{24}\left(A-c_{0}\right)^{2}$, it is immediate that:

$$
B^{*}=\Lambda
$$

d) For low levels of both moral costs and entry fee, $\Lambda<\frac{1}{9}\left(A-c_{0}\right)^{2}-F$ and $F<\frac{1}{24}\left(A-c_{0}\right)^{2}$, the optimal incumbent's bribe is:

$$
B^{*}=\frac{1}{9}\left(A-c_{0}\right)^{2}-F>\Lambda
$$

2. By comparing the overt and covert behavior in this case, we find out that, overall, the range of values that support covert fight under bribe competition is at most as large as that in the case of a unique bribe-payer. Indeed, while the outcomes of the cases a) and c) are identical to those in Section 5, in case b) the range of values that support bribery is always lower than its correspondent in Section 5. We get that $\Lambda_{C B}^{l} \leq \Lambda^{l}, \Lambda_{C B}^{S} \leq \Lambda^{S}$ and $\Lambda_{C B}^{c} \leq \Lambda^{c}$, where the values $\Lambda_{C B}$ stand for the threshold that separates overt from covert behavior when both rivals can bribe $(\mathrm{CB}=$ competition in bribes). The explanation of this result is the following: when both rivals can bribe, it becomes more costly for the incumbent to fight through bribery since, in the situations described by items b) and d) above, the incumbent has to bribe more than his optimal. Hence, in those situations, covert fight becomes the optimal action only if this supplementary cost is "compensated" by a lower "risk" of bribe rejection, that is, by a larger probability of the bribe being accepted (lower values of $\Lambda$ ).

\footnotetext{
${ }^{17}$ For relatively large entry fee, namely $F \geq \frac{1}{24}\left(A-c_{0}\right)^{2}$, we have that $\frac{5}{72}\left(A-c_{0}\right)^{2} \geq$ $\frac{1}{9}\left(A-c_{0}\right)^{2}-F$
} 


\subsection{Positive Initial Production Capacity}

The second extension of our model regards the case in which the incumbent has a positive production capacity before the game starts. Then, at date $\mathbf{0}$ his problem is to choose between bribing (covert fight) or installing additional production capacity in order to overtly maximize his profits. We start from the natural assumption that an incumbent already operating in the market installed, at the beginning of his activity, the monopoly capacity, that is, the initial capacity is $k_{0}=\frac{1}{2}\left(A-c_{0}\right)^{2}$. Under such an assumption, we find that covert fight is played in most situations. The only cases when overt behavior is preferred to the covert one are those in which the entry fee is large, supporting blockaded monopoly or limit pricing and, in addition, corruption is low $(\Lambda$ is large).

Such results are rather intuitive. An incumbent who has already an installed production capacity equal to the monopoly output is extremely powerful on the market. Then, when strategic accomodation is his optimal overt behavior ${ }^{18}$, he always prefers the covert fight. The explanation is that, in such cases, i) if the bribe is rejected, the incumbent's initial production capacity still allows him to play the optimal overt action at no extra cost; ii) if the public official accepts the bribe, then the incumbent maintains a monopoly position and he gets, net of the bribe, more than the overt profits.

The only case here, in which the incumbent really faces a decision problem between overt and covert fight is when limit pricing is the optimal overt action. This is due to the fact that in such a situation the limit quantity is larger than the installed monopoly capacity, $q^{l}>q^{m}$. Then, limit pricing "beats" covert fight whenever the entry fee is relatively large (determining a low $q_{l}$ ) and corruption is low,

$$
\max \left\{\frac{1}{9}\left(A-2 c_{0}\right)^{2}, \frac{(3-2 \sqrt{2})}{32}\left(A-c_{0}\right)^{2}\right\} \leq F<\frac{1}{16}\left(A-c_{0}\right)^{2}, c_{0}>\frac{1}{5} A
$$

and

$$
\Lambda \geq \frac{\left(A-c_{0}\right)^{4}}{-32\left(A-c_{0}\right)^{2}+512 \sqrt{F}\left(A-c_{0}\right)-1024 F} .
$$

\subsection{Unbounded support of the moral costs}

Finally, we relax the assumption that the moral cost, $\lambda \sim U[0, \Lambda]$. We assume instead, that the support of $\lambda$ is infinite and that the moral cost of a dishonest behavior which characterizes the public employee follows an exponential distribution,

$$
F(x)=\operatorname{Pr}(\lambda \leq x)=1-e^{-\gamma x}
$$

where the parameter $\gamma$ represents the perceived degree of corruption in the economy; it takes positive values, with $\gamma=0$ representing a totally honest society.

\footnotetext{
${ }^{18}$ Stackelberg is optimal when $q^{S}\left(=q^{m}\right)<\min \left\{q^{c}, q^{l}\right\}$ and Cournot is the best overt action when $q^{c}<\min \left\{q^{S}\left(=q^{m}\right), q^{l}\right\}$
} 
Repeating the reasoning in section 3 we find the profit that the incumbent expects from a covert behavior,

$$
E \Pi^{B}=\left(1-e^{-\gamma B}\right)\left(\Pi^{m}-B\right)+e^{-\gamma B} \Pi^{c}
$$

The optimal bribe, $B^{*}$, which maximizes this expected payoff, has to verify the first order condition:

$$
\gamma e^{-\gamma B}\left(\Pi^{m}-\Pi^{c}\right)-\gamma e^{-\gamma B} \cdot B-1+e^{-\gamma B}=0
$$

The following result is proved in subsection 5 of the appendix:

Proposition 6. There exists a bribe $B^{*} \in\left(0,\left(\Pi^{m}-\Pi^{c}\right)\right)$ which maximizes the expected profits from covert fight. The optimal bribe under infinite support is increasing with $\left(A-c_{0}\right)$ and decreasing with the level of corruption.

This result implies that the optimal bribe is increasing with the dimension of the market and decreases with the capacity-costs. This replicates what we found for the more restrictive case in which $\lambda$ has a finite support. In addition, the statement above establishes that the larger is the level of corruption in the economy the lower is the optimal bribe that an incumbent should offer in a covert fight. The explanation stands in the fact that the larger is $\gamma$ the higher is the probability that the public employee has a low moral cost and this increases the probability of the (a lower) bribe being accepted.

Going further with our analysis, we compare the expected profit from covert fight with the profit that the incumbent can get from an optimal overt behavior. We find that for every optimal overt action there exists a level of corruption $\gamma^{o}$ such that $E \Pi^{B}\left(\gamma^{o}\right)=\Pi^{o}$, (where the upper index o stands for the optimal overt action of the incumbent). For every level of corruption larger than the threshold, $\gamma>\gamma^{o}$, the incumbent's optimal strategy is covert fight. If, instead, the degree of corruption in the economy is lower than $\gamma^{o}$ the incumbent prefers overt behavior.

This result is exactly what Proposition 2 in Section 5 states. It is not difficult to prove that also the previous Proposition 3 remains valid in this case. We remind that Proposition 3 states that the incentive to fight covertly is stronger, the stronger is the competitive pressure on the market. Mathematically such a result is represented by an ordering of the thresholds. The lowest threshold is that corresponding to an optimal Cournot, followed by the threshold corresponding to Stackelberg and finally by that of limit pricing ${ }^{19}$ :

$$
\gamma^{l}>\gamma^{S}>\gamma^{c k}
$$

The unique result of the previous case which does not hold anymore is Proposition 4 ; in this situation the probability that entry is deterred by corrupt

\footnotetext{
${ }^{19}$ Note that a lower threshold means in this case a larger range of values $\gamma$ which support covert fight
} 
behavior is never 1 . This is not surprising under the assumption of infinite support for $\lambda$, given that it is not possible anymore for the incumbent to bribe the maximum moral cost of the public official, which is infinite.

Given the above findings we can conclude that the qualitative results that we obtained under a uniform distribution of $\lambda$ hold also for the case with infinite support and hence that the previous results are robust to changes in the support and the distribution of the moral cost.

\section{Conclusions}

In the present paper we identify in which situations and to what extent the degree of corruption affects the level of competition on the market.

When the entry fee is high the incumbent prefers an overt fight even for high levels of corruption. If the entry fee is not so large as to support blockaded monopoly, covert behavior may become the optimal strategy for an incumbent, when the degree of corruption in the public sector is significantly large. In such cases bribery may reduce competition and hence, it represents a real alternative to limit pricing or a substitute of limit pricing when the optimal overt action is Stackelberg or Cournot. Given a covert behavior of the incumbent, the probability that the entrant is denied the production licence and entry does not occur is:

$$
\operatorname{Pr}(\text { no entry })=\operatorname{Pr}\left(\lambda<B^{*}\right)=\min \left\{\frac{5}{72 \Lambda}\left(A-c_{0}\right)^{2}, 1\right\}
$$

decreasing with $\Lambda^{20}$ and increasing with the difference $\left(A-c_{0}\right)$.

For low probability of corruption and low levels of the entry fee (the most desirable case) strategic accomodation is the optimal choice of the incumbent who decides, based on the level of the capacity cost, to play Stackelberg or Cournot. In such situations the alternative covert behavior has no effect on competition.

The level of the entry fee can be an extremely important political instrument. Depending on the environment, and we think here mainly about the levels of corruption and the market characteristics: dimensions and production costs, the entry fee can exert two important effects.

1. In economies where the level of corruption is low, practicing low levels of entry fees can be a good instrument to diminish the negative effects of "limit pricing". This happens essentially because a low entry fee induces a large limit quantity, $q^{l}$. The implications are the following:

- low entry fee may make unattractive a limit pricing strategy for the incumbent; large $q^{l}$ can prove not to be optimal for the incumbent but, instead, to be dominated by a policy of strategic entry accomodation. On the contrary, a high entry fee may lead to situations of blockaded

\footnotetext{
${ }^{20}$ The expected moral cost of a public employee from a dishonest behavior is positively related to $\Lambda$.
} 
monopoly which totally favor the incumbent allowing him to behave like a monopolist.

- When practicing $q^{l}$ is the best alternative for the incumbent, low $F$ determines an increase in supply and consequently reduces equilibrium price despite the fact that the incumbent manages to deter entry.

So we can say that a low entry fee makes supply closer to the competitive one, even when the incumbent practices a policy of limit pricing, leading to higher levels of consumer surplus and social welfare while reducing the incumbent's power (determines an increase in the social welfare and a more fair distribution of the surplus in the economy).

2. However, in particularly corrupt environments, low levels of the entry fee may increase the incentive of an incumbent to behave dishonestly by offering bribes. Being too costly to "fight" overtly (by practicing limit pricing), due to the high levels of $q_{l}$ that a low entry fee induce, an incumbent would find it more attractive to use covert means in order to deter entry and maintain his monopolistic power. This is particularly dangerous especially in countries where the level of corruption is high which makes credible and highly probable the fact that public officials are ready to abuse the decision power with which they were invested, and behave dishonestly in exchange for a bribe. According to Ades and Di Tella (1999) the probability of corruption is inversely related to the amount of the employee's wage. This implies that poorer countries bare more risk of reduced market competition due to corruption.

From a social point of view corruption has negative effects since in most situations the level of consumers' surplus and/or social welfare are lower under covert than under overt behavior.

On the same ground of social implications the perceived level of corruption may have important indirect effects on the outcomes. We can think of $\Lambda$ as the society perception of the corruption level in the public sector. Such a perception, be it correct or not, determines the optimal choice of the incumbent: if the incumbent perceives a high level of corruption he chooses a covert, bribery behavior. If, despite initial perceptions, the public official has a large moral cost and the bribe is rejected, Cournot competition occurs. Depending on the corresponding optimal overt action of the incumbent we can identify two opposite effects. On one hand, there may be a negative effect: if the optimal honest action is Stackelberg then, playing Cournot leads to lower surpluses/welfare levels. On the other hand, there can be a positive effect: if the optimal overt action is limit pricing, bribery still guarantees a positive probability of entry.

\section{References}

Ades, A., and R. Di Tella (1996): "The Causes and Consequences of Corruption," IDS Bulletin, 27, 6-10.

(1999): "Rents, Competition and Corruption," The American Economic Review, 89, 982-993. 
Arnone, M., ANd E. Iliopulis (2005): La corruzione costa: effetti economici, istituzionali e sociali. Vita e Pensiero, Milano, first edition edn.

Bliss, C., And R. Di Tella (1997): "Does Competition Kill Corruption?," The Journal of Political Economy, 105, 1001-1003.

Church, J., and R. Ware (2001): Industrial Organization: A Strategic Approach. Irwin, McGraw-Hill.

Dixit, A. (1980): "The Role of Investment in Entry Deterrence," The Economic Journal, 90, 95-106.

Gurgur, T., and A. Shah (2005): "Localization and Corruption," World Bank Policy Research Working Paper 3486, 1-35.

Rose-Ackerman, S. (1975): "The Economics of Corruption," Journal of Public Economics, 4, 187-203.

TAnzI, V. (1998): "Corruption Around the World: Causes, Consequences, Scope and Cures," IMF Staff Papers, 45, 559-594.

Tirole, J. (1994): The Theory of Industrial Organization. MIT Press, Cambridge. 


\section{A Appendix}

\section{A.1 Outcomes and Payoffs of Overt and Covert Subgames}

We reproduce here the outcomes and payoffs of the different types of competition, which we use for identifying the optimal incumbent's action.

Monopoly outcomes.

$$
\begin{gathered}
q^{m}=\frac{1}{2}\left(A-c_{0}\right), \quad p^{m}=\frac{1}{2}\left(A+c_{0}\right), \quad \Pi^{m}=\frac{1}{4}\left(A-c_{0}\right)^{2} \\
W^{m}=\frac{3}{8}\left(A-c_{0}\right)^{2}, \quad S_{c}^{m}=\frac{1}{8}\left(A-c_{0}\right)^{2}
\end{gathered}
$$

Cournot outcomes when incumbent capacity is $k=0$.

$$
\begin{aligned}
q_{i}^{c}=q_{e}^{c}=\frac{1}{3}\left(A-c_{0}\right), p^{c} & =\frac{1}{3}\left(A+2 c_{0}\right), \quad \Pi_{i}^{c}=\frac{1}{9}\left(A-c_{0}\right)^{2}, \quad \Pi_{e}^{c}=\frac{1}{9}\left(A-c_{0}\right)^{2}-F \\
W^{c} & =\frac{4}{9}\left(A-c_{0}\right)^{2}, \quad S_{c}^{c}=\frac{2}{9}\left(A-c_{0}\right)^{2}
\end{aligned}
$$

Cournot outcomes when incumbent capacity is $k=+\infty$.

$$
\begin{gathered}
q_{i}^{c k}=\frac{1}{3}\left(A+c_{0}\right), q_{e}^{c k}=\frac{1}{3}\left(A-2 c_{0}\right), p^{c k}=\frac{1}{3}\left(A+c_{0}\right), \quad \Pi_{i}^{c k}=\frac{1}{9}\left(A^{2}-c_{0} A-2 c_{0}^{2}\right), \Pi_{e}^{c k}=\frac{1}{9}\left(A-2 c_{0}\right)^{2}-F \\
W^{c k}=\frac{1}{18}\left(8 A^{2}-14 c_{0} A+5 c_{0}^{2}\right), \quad S_{c}^{c k}=\frac{1}{18}\left(2 A-c_{0}\right)^{2}
\end{gathered}
$$

Limit pricing outcomes. The limit quantity is the quantity that the incumbent should commit to produce so as to make null the profits of the entrant:

$$
\begin{gathered}
q^{l}=A-c_{0}-2 \sqrt{F}, \quad p^{l}=c_{0}+2 \sqrt{F}, \quad \Pi^{l}=2 \sqrt{F}\left(A-c_{0}\right)-4 F \\
W^{l}=\frac{1}{2}\left(A-c_{0}\right)^{2}-2 F, \quad S_{c}^{l}=\frac{1}{2}\left(A-c_{0}-2 \sqrt{F}\right)^{2}
\end{gathered}
$$

Stackelberg outcomes. The Stackelberg quantities are:

$$
\begin{gathered}
q_{i}^{s}=\frac{1}{2}\left(A-c_{0}\right) q_{e}^{s}=\frac{1}{4}\left(A-c_{0}\right), p^{s}=\frac{1}{4}\left(A+3 c_{0}\right), \Pi_{i}^{s}=\frac{1}{8}\left(A-c_{0}\right)^{2}, \Pi_{e}^{s}=\frac{1}{16}\left(A-c_{0}\right)^{2}-F \\
W^{s}=\frac{15}{32}\left(A-c_{0}\right)^{2}, \quad S_{c}^{s}=\frac{9}{32}\left(A-c_{0}\right)^{2}
\end{gathered}
$$


Covert fight. We compute hereafter the incumbent's expected profit, the expected social welfare and the consumers' surplus under a covert incumbent's behavior. We separately analyze the cases with low and high corruption respectively.

- medium-low corruption (optimal bribe, $B^{*}=\frac{1}{2}\left(\Pi^{m}-\Pi_{i}^{c}\right)$ ):

$$
\begin{aligned}
E \Pi^{B} & =\operatorname{Pr}\left(\lambda \leq B^{*}\right)\left(\Pi^{m}-B^{*}\right)+\operatorname{Pr}\left(\lambda>B^{*}\right) \Pi_{i}^{c} \\
& =\frac{B^{*}}{\Lambda}\left(\Pi^{m}-B^{*}\right)+\left(1-\frac{B^{*}}{\Lambda}\right) \Pi_{i}^{c} \\
& =\frac{1}{9}\left(A-c_{0}\right)^{2}\left[\frac{25}{576 \Lambda}\left(A-c_{0}\right)^{2}+1\right] \\
E W^{B} & =\left(A-c_{0}\right)^{2} \cdot\left[\frac{4}{9}-\frac{25}{5184 \Lambda}\left(A-c_{0}\right)^{2}\right]
\end{aligned}
$$

while the consumers expect a surplus of:

$$
E S_{c}^{B}=\left(A-c_{0}\right)^{2} \cdot\left[\frac{2}{9}-\frac{35}{5184 \Lambda}\left(A-c_{0}\right)^{2}\right]
$$

- high corruption (optimal bribe $=\Lambda$ ):

$$
\begin{aligned}
E \Pi^{B} & =\underbrace{\operatorname{Pr}(\lambda \leq \Lambda)}_{=1}\left(\Pi^{m}-\Lambda\right)+\underbrace{\operatorname{Pr}(\lambda>\Lambda)}_{=0}\left(\Pi_{i}^{c}\right) \\
& =\Pi^{m}-\Lambda \\
& =\frac{1}{4}\left(A-c_{0}\right)^{2}-\Lambda \\
E W^{B}= & W^{m}=\frac{3}{8}\left(A-c_{0}\right)^{2}, \quad E S_{c}^{B}=S_{c}^{m}=\frac{1}{8}\left(A-c_{0}\right)^{2}
\end{aligned}
$$

\section{A.2 Proofs of Propositions 2 and 5}

Proof of Proposition 2. The proof of this statement consists of calculations and comparisons.

In proposition 2 we refer to a situation in which corruption is relatively low, $\Lambda \geq \frac{5}{72}\left(A-c_{0}\right)^{2}$. The incumbent chooses his optimal action (overt or covert fight) on the basis of his payoffs. Based on the levels of the entry fee and capacity cost, which determine the best overt action, we can distinguish the following situations:

1. Limit pricing versus bribe: By comparing the profits from the two actions we get:

$$
E \Pi^{B}-\Pi^{l}=\frac{1}{9}\left(A-c_{0}\right)^{2}+\frac{25}{5184 \Lambda}\left(A-c_{0}\right)^{4}-2 \sqrt{F}\left(A-c_{0}\right)+4 F
$$


This expression is positive (and hence $E \Pi^{B} \geq \Pi^{l}$ ) if and only if:

$$
\Lambda \leq \Lambda^{l}=\frac{25\left(A-c_{0}\right)^{4}}{5184\left(-4 F+2 \sqrt{F}\left(A-c_{0}\right)-\frac{1}{9}\left(A-c_{0}\right)^{2}\right)}
$$

In order to establish if this situation is indeed compatible with relatively low corruption, we compare $\Lambda^{l}$ with the threshold that separates between large and low corruption, $\frac{5}{72}\left(A-c_{0}\right)^{2}$ :

$$
\Lambda^{l}-\frac{5}{72}\left(A-c_{0}\right)^{2}=\frac{25\left(A-c_{0}\right)^{4}}{5184\left(-4 F+2 \sqrt{F}\left(A-c_{0}\right)-\frac{1}{9}\left(A-c_{0}\right)^{2}\right)}-\frac{5}{72}\left(A-c_{0}\right)^{2}
$$

We find that this difference is positive for $F$ which satisfy:

$F<\frac{23-6 \sqrt{10}}{288}\left(A-c_{0}\right)^{2} \approx 0.01398\left(A-c_{0}\right)^{2}$ or $F>\frac{23+6 \sqrt{10}}{288}\left(A-c_{0}\right)^{2} \approx 0.145741\left(A-c_{0}\right)^{2}$

\section{Stackelberg versus bribe:}

$$
E \Pi^{B}-\Pi_{i}^{s}=\frac{25}{5184 \Lambda}\left(A-c_{0}\right)^{2}-\frac{1}{72}
$$

We find out that this expression is positive (and hence $E \Pi^{B} \geq \Pi_{i}^{s}$ ) if and only if:

$$
\Lambda \leq \Lambda^{s}=\frac{25}{72}\left(A-c_{0}\right)^{2}
$$

\section{Cournot with capacity constraints versus bribe:}

$$
E \Pi^{B}-\Pi_{i}^{c k}=\frac{25}{5184 \Lambda}\left(A-c_{0}\right)^{4}+\frac{1}{9}\left(A-c_{0}\right)^{2}-\frac{1}{9}\left(A^{2}-A c_{0}-2 c_{0}\right)
$$

This expression is positive, meaning that the incumbent is better off under covert behavior, if and only if:

$$
\Lambda \leq \Lambda^{c}=\frac{25}{576\left(A c_{0}-3 c_{0}^{2}\right)}\left(A-c_{0}\right)^{4}
$$

Summing up the findings from these computations, we conclude that the covert behavior is always supported by high corruption, while when the degree of corruption is low ( $\Lambda$ is large), the incumbent plays overtly. This means that low corruption does not influence the competition in the market. Moreover, by analyzing the various thresholds that we have obtained we can immediately note that they are all increasing with the dimension of the market $A$, and decreasing with the capacity installing cost $c_{0}$. This completes the proof of Proposition 2. 
Proof of Proposition 5. In order to prove the three statements of Proposition 5 we need to compare the social welfare and consumers' surplus respectively, in the optimal overt action with those of the covert subgame.

1. When Stackelberg is the optimal overt action of the incumbent, comparing social welfare from covert and overt behavior we obtain:

$$
W^{s}-E W^{B}=\left(A-c_{0}\right)^{2} \cdot\left[\frac{7}{288}+\frac{25}{5184 \Lambda}\left(A-c_{0}\right)^{2}\right]
$$

and this is always positive meaning that Stackelberg always leads to higher levels of welfare than a covert behavior would do.

2. When the level of the entry fee supports Cournot, we have that:

$$
W^{c k}-E W^{B}=\frac{1}{18} c_{0}\left(2 A-3 c_{0}\right)+\frac{25}{5184 \Lambda}\left(A-c_{0}\right)^{4}
$$

and this is positive for all the values of $c_{0}$ considered. We can thus state that, from a social point of view, Cournot is always preferable to the covert fight.

3. For those levels of the entry fee that support limit pricing we have:

$$
W^{l}-E W^{B}=\frac{1}{18}\left(A-c_{0}\right)^{2}+\frac{25}{5184 \Lambda}\left(A-c_{0}\right)^{4}-2 F
$$

We can distinguish two cases:

- 3.1. $F \leq \frac{1}{36}\left(A-c_{0}\right)^{2}$. In this case $W^{l} \geq E W^{B}$ always, that is, limit pricing is always socially better than bribery.

- 3.2. $F>\frac{1}{36}\left(A-c_{0}\right)^{2}$ In this situation $W^{l} \geq E W^{B}$ only for:

$$
\Lambda<\frac{25\left(A-c_{0}\right)^{4}}{5184\left(-4 F+2 \sqrt{F}\left(A-c_{0}\right)-\frac{1}{9}\left(A-c_{0}\right)^{2}\right)}
$$

Cases 1., 2. and 3.1. prove the first statement of Proposition 5 while case $\mathbf{3 . 2}$. proves its the second part. Finally, in order to prove the third statement we only need to observe that when corruption is high the consumers' surplus and social welfare under covert fight are the monopoly ones. Hence they are always lower than those of an overt behavior.

\section{A.3 Competition in Bribes}

We perform the computations corresponding to the cases described in paragraph 1. point b) and point d) in Section 7.1. Both those cases are characterized by a low level of the entry fee, $F<\frac{1}{24}\left(A-c_{0}\right)^{2}$, and in both situations the incumbent's optimal bribe is:

$$
B^{*}=\frac{1}{9}\left(A-c_{0}\right)^{2}-F
$$


The difference between the two stands in the level of corruption which is extremely important for the incumbent's decisions. In what follows we compute separately the incumbent's expected profits from covert fight under low and under high corruption respectively.

Low corruption This is the situation when $\Lambda \geq \frac{1}{9}\left(A-c_{0}\right)^{2}-F$. Then, when behaving dishonestly, the incumbent expects a level of profits:

$$
\begin{aligned}
E \Pi^{B} & =\operatorname{Pr}\left[\lambda \leq \frac{1}{9}\left(A-c_{0}\right)^{2}-F\right] \cdot\left[\Pi^{m}-\frac{1}{9}\left(A-c_{0}\right)^{2}+F\right]+\operatorname{Pr}\left[\lambda>\frac{1}{9}\left(A-c_{0}\right)^{2}-F\right] \cdot \Pi_{i}^{c} \\
& =\frac{1}{9}\left(A-c_{0}\right)^{2}+\frac{1}{324 \Lambda}\left[\left(A-c_{0}\right)^{2}-9 F\right] \cdot\left[\left(A-c_{0}\right)^{2}+36 F\right]
\end{aligned}
$$

By comparing it with the various possible overt profits we get that:

- when limit pricing is the optimal overt action, then covert fight is preferred by the incumbent whenever:

$$
E \Pi^{B}-\Pi^{l} \geq 0
$$

that is, when:

$$
\Lambda \leq \frac{\left(A-c_{0}\right)^{4}+27\left(A-c_{0}\right)^{2} F-324 F^{2}}{36\left[-\left(A-c_{0}\right)^{2}+18 \sqrt{F}\left(A-c_{0}\right)-36 F\right]}=\Lambda_{C B}^{l}
$$

- when the level of the entry fee is such that it supports Stackelberg in an overt subgame,

$$
E \Pi^{B}-\Pi^{S}=\frac{1}{324 \Lambda}\left[\left(A-c_{0}\right)^{2}-9 F\right] \cdot\left[\left(A-c_{0}\right)^{2}+36 F\right]-\frac{1}{72}\left(A-c_{0}\right)^{2}
$$

is positive if and only if:

$$
\Lambda \leq 2 \frac{\left(A-c_{0}\right)^{4}+27\left(A-c_{0}\right)^{2} F-324 F^{2}}{9\left(A-c_{0}\right)^{2}}=\Lambda_{C B}^{S}
$$

This means that covert fight is optimal for the incumbent only when the degree of corruption in the public sector is relatively high.

- when Cournot is the incumbent's best choice in an overt subgame, by comparing the profits from an overt with those from a covert behavior we get:

$E \Pi^{B}-\Pi^{c k}=\frac{1}{324 \Lambda}\left[\left(A-c_{0}\right)^{4}+27\left(A-c_{0}\right)^{2} F-324 F^{2}\right]+\frac{1}{9}\left(3 c_{0}^{2}-c_{0} A\right)$

The above expression is positive, meaning that covert fight is preferred by the incumbent, whenever:

$$
\Lambda \leq \frac{\left(A-c_{0}\right)^{4}+27\left(A-c_{0}\right)^{2} F-324 F^{2}}{36\left(c_{0} A-c_{0}^{2}\right)}=\Lambda_{C B}^{c k}
$$


High corruption This situation is characterized by $\Lambda<\frac{1}{9}\left(A-c_{0}\right)^{2}-F=B^{*}$. Here we only need to establish the incumbent's optimal strategy when limit pricing is the best incumbent's overt action. We get that:

$$
E \Pi^{B}-\Pi^{l}=\frac{5}{36}\left(A-c_{0}\right)^{2}+5 F-2 \sqrt{F}\left(A-c_{0}\right)
$$

By evaluating the sign of this expression based on the values of $F$, we can say that covert fight is preferred by the incumbent to limit pricing whenever:

$$
\max \left\{\frac{1}{9}\left(A-2 c_{0}\right)^{2}, \frac{(3-2 \sqrt{2})}{32}\left(A-c_{0}\right)^{2}\right\} \leq F<\frac{47-12 \sqrt{11}}{900}\left(A-c_{0}\right)^{2} .
$$

"Unique bribe-payer" versus "Competition in bribes" Comparing the thresholds $\Lambda$ in the initial case, when the unique bribe-payer is the incumbent, with those obtained under bribe competition we get:

$$
\Lambda^{l}-\Lambda_{C B}^{l}=\frac{9\left[24 F-\left(A-c_{0}\right)^{2}\right]}{576\left[-\left(A-c_{0}\right)^{2}+18 \sqrt{F}\left(A-c_{0}\right)-36 F\right]}
$$

and this is larger than 0 for all valuations of $F$ supporting limit pricing.

For an entry fee that promotes Stackelberg in an overt subgame,

$$
\Lambda^{S}-\Lambda_{C B}^{S}=\frac{\left(A-c_{0}\right)^{4}-48\left(A-c_{0}\right)^{2} F+36 F^{2}}{8\left(A-c_{0}\right)^{2}} .
$$

It is easy to prove that this expression is positive, meaning that $\Lambda_{C B}^{S}<\Lambda^{S}$, for any levels of the entry fee and capacity cost which support Stackelberg.

Finally, when Cournot is the incumbent's optimal overt action,

$$
\Lambda^{c k}-\Lambda_{C B}^{c k}=\frac{\left[\left(A-c_{0}\right)^{2}-24 F\right]^{2}}{64\left(A c_{0}-c_{0}^{2}\right)}
$$

which is always positive, that is, $\Lambda_{C B}^{c k}<\Lambda^{c k}$ always, meaning that the range of values $\Lambda$ (moral costs) which support covert fight is always smaller when the rivals compete in bribes.

\section{A.4 Positive Initial Production Capacity}

We compute optimal bribe and the incumbent's expected profits under covert fight in two situations:

1. When the optimal overt action is Stackelberg or limit pricing, if the bribe is rejected in a covert fight, then Stackelberg is played. Then, the optimal bribe is:

$$
B^{*}=\min \left\{\frac{1}{2}\left(\Pi^{m}-\Pi^{S}\right), \Lambda\right\}=\min \left\{\frac{1}{16}\left(A-c_{0}\right)^{2}, \Lambda\right\}
$$


Then, under relatively low corruption, the incumbent expects:

$$
\begin{aligned}
E \Pi^{B} & =\operatorname{Pr}\left(\lambda \leq B^{*}\right)\left(\Pi^{m}-B^{*}\right)+\operatorname{Pr}\left(\lambda>B^{*}\right) \Pi_{i}^{S} \\
& =\frac{1}{256 \Lambda}\left(A-c_{0}\right)^{4}+\frac{1}{8}\left(A-c_{0}\right)\left(A+3 c_{0}\right)
\end{aligned}
$$

2. When the entry fee supports Cournot, by bribing optimally,

$$
B^{*}=\min \left\{\frac{1}{2}\left(\Pi^{m}-\Pi^{c}\right), \Lambda\right\}
$$

the incumbent's expects a profit of:

$$
E \Pi^{B}=\operatorname{Pr}\left(\lambda \leq B^{*}\right)\left(\Pi^{m}-B^{*}\right)+\operatorname{Pr}\left(\lambda>B^{*}\right) \Pi_{i}^{c}
$$

\section{A.5 Unbounded support of the moral costs}

Proof of proposition 6

We first prove that there exists $B^{*}$ comprised between $\left(0,\left(\Pi^{m}-\Pi^{c}\right)\right)$ that maximizes the expected profits from covert fight. When fighting covertly, the incumbent chooses the amount of bribe which maximizes his expected profits:

$$
\max _{B} E \Pi^{B}=\left(1-e^{-\gamma B}\right)\left(\Pi^{m}-B\right)+e^{-\gamma B} \Pi^{c}
$$

The optimal bribe should verify the first order condition,

$$
\frac{\partial E \Pi}{\partial B}=\gamma e^{-\gamma B}\left(\Pi^{m}-\Pi^{c}\right)-\gamma e^{-\gamma B} \cdot B-1+e^{-\gamma B}=0
$$

By evaluating the derivative of the expected profits with respect to bribe in the point $B=0$ and $B=\left(\Pi^{m}-\Pi^{c}\right)$ we get:

$\frac{\partial E \Pi}{\partial B}(B=0)=\gamma\left(\Pi^{m}-\Pi^{c}\right)>0, \frac{\partial E \Pi}{\partial B}\left(B=\left(\Pi^{m}-\Pi^{c}\right)\right)=\exp ^{-\gamma\left(\Pi^{m}-\Pi^{c}\right)}-1<0$

Given that the function $\frac{\partial E \Pi}{\partial B}$ is continuous in $B$ we can conclude, by the intermediate value theorem, that there exists $B^{*} \in\left(0,\left(\Pi^{m}-\Pi^{c}\right)\right)$ such that $\frac{\partial E \Pi}{\partial B}\left(B^{*}\right)=0$. In addition, since $\frac{\partial E \Pi}{\partial B}$ is strictly decreasing in $B$ on the interval $\left(0,\left(\Pi^{m}-\Pi^{c}\right)\right)$, we can establish that $B^{*}$ is unique.

For $B^{*}$ to correspond to a maximum the second order condition should be satisfied. We get:

$$
\frac{\partial^{2} E \Pi}{\partial B^{2}}=-\gamma^{2} e^{-\gamma B}\left(\Pi^{m}-\Pi^{c}\right)+\gamma^{2} e^{-\gamma B} \cdot B-2 \gamma e^{-\gamma B}
$$

By reordering, this can be written:

$$
\frac{\partial^{2} E \Pi}{\partial B^{2}}=-\gamma e^{-\gamma B}\left[\gamma\left(\Pi^{m}-\Pi^{c}-B\right)+2\right]
$$


which is always negative implying that $B^{*}$ corresponds indeed to a maximum.

We study now how the optimal bribe behaves when the gains from bribery or the level of corruption increase marginally. Using the implicit function theorem in the first order condition we find that:

$$
\frac{\partial B^{*}}{\partial\left(\Pi^{m}-\Pi^{c}\right)}=\frac{1}{2+\gamma\left[\left(\Pi^{m}-\Pi^{c}\right)-B^{*}\right]}
$$

This expression is always positive, given that the optimal bribe is always lower than the gains from bribing, $\left(\Pi^{m}-\Pi^{c}\right)$. Since $\left(\Pi^{m}-\Pi^{c}\right)$ depends positively on the amount $\left(A-c_{0}\right)$, this implies that the optimal bribe increases with the dimension of the market and decreases with the capacity-costs.

Applying the implicit function theorem with respect to the level of corruption $\gamma$ we get:

$$
\frac{\partial B^{*}}{\partial \gamma}=-\frac{e^{-\gamma B^{*}}\left[\left(\Pi^{m}-\Pi^{c}\right)-\gamma B^{*}\left(\Pi^{m}-\Pi^{c}\right)-2 B^{*}+\gamma B^{* 2}\right]}{-\gamma e^{-\gamma B^{*}}\left\{2+\gamma\left[\left(\Pi^{m}-\Pi^{c}\right)-B^{*}\right]\right\}}
$$

Using the first order condition we simplify the above expression and obtain:

$$
\frac{\partial B^{*}}{\partial \gamma}=\frac{1-e^{-\gamma B^{*}}-\gamma B^{*}}{\gamma^{2} e^{-\gamma B^{*}}\left\{2+\gamma\left[\left(\Pi^{m}-\Pi^{c}\right)-B^{*}\right]\right\}}
$$

The denominator of this expression is always positive and we can easily prove that the numerator has always a negative sign (the expression at the numerator is a decreasing function of $\gamma$ and its value for $\gamma=0$ is 0 ). Consequently, the derivative of the optimal bribe with respect to the degree of corruption $\gamma$ is negative. This implies that the larger is the level of corruption in the economy the lower is the optimal bribe that an incumbent should offer in a covert fight.

And this completes the proof of Proposition 6.

The optimal bribe under infinite support is given by:

$$
B^{*}=\frac{1-\text { Lambert } \mathrm{W}\left(e^{1+\gamma\left(\Pi^{m}-\Pi^{c}\right)}\right)+\gamma\left(\Pi^{m}-\Pi^{c}\right)}{\gamma}
$$

We prove now the validity of Proposition 2 and Proposition 3 in the case with unbounded support of the moral costs.

Stackelberg vs. bribery Comparing the profits under bribery with those under Stackelberg we get:

$$
E \Pi^{B}-\Pi^{S}=\left(1-e^{-\gamma B^{*}}\right)\left(\Pi^{m}-B^{*}\right)+e^{-\gamma B^{*}} \Pi^{c}-\Pi^{S}
$$

Substituting $\Pi^{S}=\frac{1}{2} \Pi^{m}$ into the above expression, by simplifying and reordering we get:

$$
E \Pi^{B}-\Pi^{S}=\frac{1}{2} \Pi^{m}-B^{*}-e^{-\gamma B^{*}}\left[\left(\Pi^{m}-\Pi^{c}\right)-B^{*}\right]
$$


A different form of the above expression is:

$$
E \Pi^{B}-\Pi^{S}=\frac{1}{2} \Pi^{m}-B^{*}-\frac{1}{\gamma}+\frac{e^{-\gamma B^{*}}}{\gamma}
$$

which we obtain by using the first order condition (2), for appropriate substitutions. Computing $E \Pi^{B}-\Pi^{S}$ in the point $\gamma=0^{21}$ we get:

$$
\begin{aligned}
\left(E \Pi^{B}-\Pi^{S}\right)(\gamma=0) & =\frac{1}{2} \Pi^{m}-B^{*}(0)-e^{0}\left[\left(\Pi^{m}-\Pi^{c}\right)-B^{*}(0)\right] \\
& =\Pi^{c}-\frac{1}{2} \Pi^{m}<0
\end{aligned}
$$

When $\gamma \rightarrow \infty$ instead, we have:

$$
\begin{aligned}
\lim _{\gamma \rightarrow \infty}\left(E \Pi^{B}-\Pi^{S}\right) & =\lim _{\gamma \rightarrow \infty}\left(\frac{1}{2} \Pi^{m}-B^{*}+\frac{e^{-\gamma B^{*}}}{\gamma}-\frac{1}{\gamma}\right) \\
& =\lim _{\gamma \rightarrow \infty}\left(\frac{1}{2} \Pi^{m}-B^{*}\right)+\lim _{\gamma \rightarrow \infty} \frac{e^{-\gamma B^{*}}}{\gamma}
\end{aligned}
$$

We can easily prove that $B^{*}<\frac{1}{2}\left(\Pi^{m}-\Pi^{c}\right)<\frac{1}{2} \Pi^{m}$ since

$$
\frac{\partial E \Pi^{B}}{\partial B}\left(B=\frac{1}{2}\left(\Pi^{m}-\Pi^{c}\right)\right)<0
$$

Consequently, the expression in the limit above is positive.

Given the above considerations and taking into account that the function $\left(E \Pi^{B}-\Pi^{S}\right)(\gamma)$ is continuous we can conclude, by the intermediate value theorem, that there exists $\gamma^{S}$ such as:

$$
\left(E \Pi^{B}-\Pi^{S}\right)\left(\gamma^{S}\right)=0 \Leftrightarrow E \Pi^{B}\left(\gamma^{S}\right)=\Pi^{S}
$$

In addition, since $\left(E \Pi^{B}-\Pi^{S}\right)(\gamma)$ is strictly increasing in $\gamma$,

$$
\frac{\partial\left(E \Pi^{B}-\Pi^{S}\right)}{\partial \gamma}=\frac{\partial E \Pi^{B}}{\partial \gamma}=e^{-\gamma B^{*}} B^{*}\left[\left(\Pi^{m}-\Pi^{c}\right)-B^{*}\right]>0
$$

we can state that $\gamma^{S}$ is unique and that for all $\gamma>\gamma^{S}$ it is verified that $E \Pi^{B}>$ $\Pi^{S}$ while the inverse is true for levels of corruption $\gamma<\gamma^{S}$

Applying the implicit function theorem we find,

$$
\frac{\partial \gamma^{S}}{\partial\left(A-c_{0}\right)}=-\frac{\left(E \Pi^{B}-\Pi^{S}\right)_{A-c_{0}}^{\prime}\left(\gamma^{S},\left(A-c_{0}\right)\right)}{\left(E \Pi^{B}-\Pi^{S}\right)_{\gamma}^{\prime}\left(\gamma^{S},\left(A-c_{0}\right)\right)}
$$

\footnotetext{
${ }^{21}$ Note that there is no problem in evaluating $B^{*}(0)$ since we know that $B^{*}$ is decreasing in $\gamma$ and it is always lower than $\left(\Pi^{m}-\Pi^{c}\right)$.
} 
Computing $\left(E \Pi^{B}-\Pi^{S}\right)_{A-c_{0}}^{\prime}$ we obtain,

$$
\begin{aligned}
\left(E \Pi^{B}-\Pi^{S}\right)_{A-c_{0}}^{\prime}= & \frac{1}{4}\left(A-c_{0}\right)+\frac{\partial B^{*}}{\partial\left(A-c_{0}\right)} \underbrace{\left(\gamma^{S} e^{-\gamma^{S} B^{*}}\left(\Pi^{m}-\Pi^{c}\right)-\gamma^{S} e^{-\gamma^{S} B^{*}} \cdot B^{*}-1+e^{-\gamma B^{*}}\right)}_{=0 \text { by FOC }}- \\
& -\frac{5}{18}\left(A-c_{0}\right) e^{-\gamma^{S} B^{*}} \\
& =\frac{1}{4}-\frac{5}{18}\left(A-c_{0}\right) e^{-\gamma^{S} B^{*}}
\end{aligned}
$$

From the equality

$$
E \Pi^{B}\left(\gamma^{S}\right)-\Pi^{S}=0
$$

we get:

$$
\frac{1}{4}\left(A-c_{0}\right)-\frac{5}{18}\left(A-c_{0}\right) e^{-\gamma^{S} B}=\frac{2}{\left(A-c_{0}\right)} B^{*}\left(1-e^{-\gamma^{S} B^{*}}\right)
$$

But the right hand side of this expression is positive and this implies that also expression (7) is positive.

Using the results (5) and (7) we can evaluate the sign of the derivative of the threshold $\gamma^{S}$ with respect to $\left(A-c_{0}\right)$ (expression $\left.(7)\right)$ and we conclude that this is always negative. This means that the threshold $\gamma^{S}$ is decreasing with the market dimension but increasing with the amount of the capacity costs.

Cournot vs. bribery Using exactly the same technique as for Stackelberg we can prove that there exists $\gamma^{c}$ such that $E \Pi^{B}\left(\gamma^{c}\right)=\Pi_{i}^{c k}\left(\gamma^{c}\right)$ and that $\gamma^{c}$ has the same properties as $\gamma^{S}$ (decreasing with $A$ and increasing with $c_{0}$ ).

Limit pricing vs. bribery The proof of existence of $\gamma^{l}$ is not as easy as in the previous two cases. However, we are able to prove, without using the mathematical expression of $B^{*}$, that $\gamma^{l}$ exists at least for relatively low levels of $F$. In addition, we can show in the same way as for Stackelberg that whenever $\gamma^{S}$ exists, it is decreasing in the amount $\left(A-c_{0}\right)$ implying that the threshold is decreasing with $A$ and increasing with $c_{0}$.

Proof of Proposition 3:

We prove this statement by observing that:

- $E \Pi^{B}$ is continuous and increasing in $\gamma$;

- $\gamma^{l}$ satisfies $E \Pi\left(\gamma^{l}\right)=\Pi^{l}\left(F^{l}, A^{l}, c_{0}^{l}\right), \gamma^{S}$ satisfies $E \Pi\left(\gamma^{S}\right)=\Pi^{S}\left(F^{S}, A^{S}, c_{0}^{S}\right)$ and $\gamma^{c k}$ satisfies $E \Pi\left(\gamma^{c k}\right)=\Pi^{c k}\left(F^{c k}, A^{c k}, c_{0}^{c k}\right)$, where $\left(F^{a}, A^{a}, c_{0}^{a}\right)$ represent those levels of $F, A$ and $c_{0}$ which support action $a$ as the optimal overt action. 
- $\Pi^{l}$ for those levels of $F, A$ and $c_{0}$ which support limit pricing is larger than $\Pi^{S}$ for those levels of $F, A$ and $c_{0}$ which support Stackelberg and this is larger than $\Pi_{i}^{c k}$ of an optimal Cournot:

$$
\Pi^{l}\left(F^{l}, A^{l}, c_{0}^{l}\right)>\Pi^{S}\left(F^{S}, A^{S}, c_{0}^{S}\right)>\Pi^{c k}\left(F^{c k}, A^{c k}, c_{0}^{c k}\right)
$$

From the considerations above we can conclude that: $\gamma^{l}>\gamma^{S}>\gamma^{c k}$. 